\title{
Retraction Note: An auxiliary training system for swimming in coastal areas based on remote sensing images and virtual simulation technology
}

\author{
Peng $\mathrm{Hou}^{1} \cdot$ Yuwen $\mathrm{Ning}^{2} \cdot$ Yaowei Song ${ }^{3}$
}

Published online: 9 December 2021

(c) Saudi Society for Geosciences 2021

Retraction Note: Arabian Journal of Geosciences (2021) 14: 583 https://doi.org/10.1007/s12517-021-06925-7

The Editor-in-Chief and the Publisher have retracted this article because the content of this article is nonsensical. The peer review process was not carried out in accordance with the Publisher's peer review policy. Authors Peng Hou and Yuwen Ning have not responded to correspondence regarding this retraction. The Publisher has not been able to obtain a current email address for author Yaowei Song.

The original article can be found online at https://doi.org/10.1007/ s12517-021-06925-7.

Yuwen Ning

ningyuwen2020@126.com

1 Department of Physical Education, Xidian University, Xi' an 710071, Shaanxi, China

2 Information Technology Center, The Fourth Military Medical University, Xi' an 710032, Shaanxi, China

3 Institute of Physical Education, Xi' an Physical Education University, Xi' an 710068, Shaanxi, China 